'Professional pathology. Course of Occupational Diseases' (1930), as well as two manuals published in 1936 - 'Labour Hygiene' edited by V.Levitsky and 'Occupational Diseases' edited by G.Arnautov, I.Gelman and B.Kogan.

In the second half of the 20th century, the scientific and educational works of N.Lazarev, N.Pravdin, I.Razenkov, E. Andreeva-Galanina, L.Khotsyanov, Z.Smelyanskiy, A.Letavet, A. Guskova, I.Sanotsky, B.Velichkovsky, V.Artamonova, and of course N.Izmerov.

It was under the editorship of N.Izmerov, for the first time in Russia, the 'Russian Encyclopaedia of Occupational Medicine' (2005) and 'Professional Pathology. National leadership '(2011).

\section{OCCUPATIONAL HEALTH IN RUSSIA: SCIENCE AND THE DEVELOPMENT OF SOCIETY}

E Shigan. FSBSI Izmerov Research Institute of Occupational Health, Moscow, Russian Federation

\subsection{6/oemed-2018-ICOHabstracts.539}

Russian scientists in XIX century Fedor Erismann, Alexander Pogozhev, Alexander Nikitin, Vladimir Svyatlovskiy, already at the early stages of Russian industry development began to think about improving working conditions. With the emergence of new high-tech industries during the XIX-XXI centuries the scientific priorities of $\mathrm{OH}$ research have also changed. By the end of the XIX century, with the transition of the main labour of workers from crafts to industry, new directions of these studies also arise. The division of industry into extractive, processing and smaller subspecies led to the emergence of such a concept as sectoral occupational health.

This was most vividly represented in the USSR: already 20 years after the victory of the Great October Revolution, 18 research institutes were active in the country. Due to the presence of various industries and agriculture in the regions, they specialised in studying local issues of $\mathrm{OH}$.

The Leningrad and Gorky institutes were pioneers in the study of toxicology and vibration disease: in the northeast of Russia and Volga-region there are many heavy engineering and chemical industries. The Kiev and Saratov institutes have always been more focused on agricultural workers`s health. Donetsk, Krivoy Rog and Novokuznetsk institutes dealt with the problems of diseases of miners and workers in the mining industry. The Yerevan and Tbilisi institutes studied the issues of preserving the health of tea-growers, workers in the tobacco and food industries.

At the turn of the 20th and 21 st centuries, special attention is paid to studying the impact of computer and new information technologies on worker`s health. The appearance in this regard of many new diseases adds them to the classification list of occupational diseases.

The development of new technologies and generates new risk factors and entails the development of new directions in the formation of the modern state of $\mathrm{OH}$.

\section{THE 95TH ANNIVERSARY OF THE WORLD'S OLDEST SCIENTIFIC INSTITUTION FOR OCCUPATIONAL DISEASES}

E Shigan, I Bukhtiyarov, L Prokopenko, N Rubtsova, L Kuzmina, N Izmerova. FSBSI Izmerov Research Institute of Occupational Health, Moscow, Russian Federation

10.1136/oemed-2018-ICOHabstracts.540
June 20, 1923, in Moscow was founded the world's oldest scientific institute of OD. It was organised as a scientific and clinical institution for the study of OD in close connexion with the hygienic methods of analysing and evaluating working conditions.

From the first days the institute continues to actively develop the preventive direction of domestic medicine, being the scientific and methodological centre of the country for a comprehensive study of the impact of occupational workers health factors and the development of scientifically based measures to prevent their adverse effects.

The development of theoretical foundations for establishing general patterns and mechanisms of the influence of factors of the production, non-productive environment and the labour process on the workers' health was actively pursued with the aim of justifying effective methods for the prevention, diagnosis, treatment and rehabilitation of OD; studying medical and social problems of the health status and dynamics of workers in connexion with demographic shifts, changing production conditions, the environment and migration processes; Improvement and development of new preventive technologies that ensure the preservation of workers' health; Including the safety of nanomaterials and nanotechnologies; development of principles and methods for using the data of socio-hygienic and epidemiological studies of production contingents in the system of insurance medicine, depending on the state of working conditions and their consequences (morbidity, mortality, disability, etc.); development of scientifically based approaches to the assessment and management of occupational risk, taking into account modern concepts.

It is enough to name Ivan Razenkov, Nikolai Pravdin, Zinoviy Smelyansky, Lev Khotsyanov, August Letavet, Igor Sanotsky, German Suvorov, Elena Vorontsova, Angelina Guskova, Nikolai Izmerov to understand the level of the scientific potential of the institution.In 1975 the Institute became the WHO Collaborating Centre of $\mathrm{OH}$, and in 1992 held the first meeting of the WHO $\mathrm{CC}$ of $\mathrm{OH}$.

\section{WORKPLACE INTERVENTIONS WITH RESPECT TO RISK MANAGEMENT MEASURES AND THEIR IMPACT ON EXPOSURE LEVELS TO HAZARDOUS SUBSTANCES - LITERATURE REVIEW}

Susann Wothe. Federal Institute for Occupational Safety and Health (BAA), Unit 4.1 Exposure Scenarios, Dortmund, Germany

\subsection{6/oemed-2018-ICOHabstracts.541}

Introduction Intervention studies play an important role in supporting and complementing scientific validation of results of non-intervention assessments of the efficacy of risk management measures (RMMs) under controlled conditions. We are reviewing a collection of published workplace intervention studies with particular focus on studies assessing the impact of the implementation of RMMs on changes in occupational exposure to hazardous substances with a very broad scope spanning a variety of approaches at a variety of workplaces in different industries.

Methods Workplace interventions were defined as events aimed at reducing occupational exposure to hazardous substances at the workplace due to a change in RMMs or where reductions occurred as a side effect, e.g. due to changes in the production process. Intervention studies published in 